\title{
Effect of exfoliated graphite nanoplatelets on the fracture surface morphology and the electrical resistivity of phenylethynyl-terminated polyimide
}

\author{
Donghwan Cho $^{1, \star}$, Hiroyuki Fukushima ${ }^{2}$ and Lawrence T. Drzal ${ }^{2}$ \\ ${ }^{1}$ Department of Polymer Science and Engineering, Kumoh National Institute of Technology, Gumi 730-701, Korea \\ ${ }^{2}$ Composite Materials and Structures Center, Michigan State University, East Lansing, MI 48824-1226, USA
}

\author{
Article Info \\ Received 19 January 2012 \\ Accepted 1 April 2012 \\ *Corresponding Author \\ E-mail: dcho@kumoh.ac.kr \\ Tel: +82-54-478-7688

\section{Open Access} \\ DOI: http://dx.doi.org/ \\ 10.5714/CL.2012.13.2.121 \\ This is an Open Access article distributed \\ under the terms of the Creative Commons \\ Attribution Non-Commercial License \\ (http://creativecommons.org/licenses/ \\ by-nc/3.0/) which permits unrestricted \\ non-commercial use, distribution, and \\ reproduction in any medium, provided \\ the original work is properly cited.
}

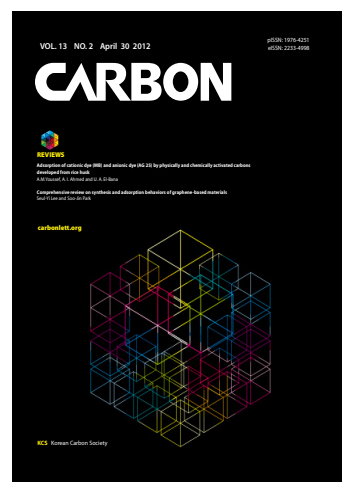

http://carbonlett.org

pISSN: $1976-4251$

elSSN: 2233-4998

Copyright $\odot$ Korean Carbon Society

\begin{abstract}
In the present work, exfoliated graphite nanoplatelets (EGN) of $1 \mu \mathrm{m}$ in average particle size, which were prepared by heating at $900^{\circ} \mathrm{C}$ and then subjected to ultrasonic, ball-milling, and vibratory ball-milling techniques, were uniformly incorporated into phenylethynyl-terminated polyimide (PETI-5) resin. The fracture surface morphology and the electrical resistivity of the EGN/PETI-5 composites were investigated. The results showed that the fracture surfaces and the electrical resistivity strongly depended on the EGN content. The fracture surfaces became more ductile and roughened with increasing EGN and the electrical resistivity was gradually decreased with increased EGN loading, indicating the percolation threshold at $5 \mathrm{wt} \% \mathrm{EGN}$.
\end{abstract}

Key words: polyimide, exfoliated graphite nanoplatelets, fracture surfaces, electrical resistivity.

\section{Introduction}

Graphite has a layered structure composed of a large number of graphene sheets held together by weak van der Waals interactions. Single crystalline graphite is one of the stiffest materials in nature with an elastic modulus of over $1 \mathrm{TPa}$. It also has a low density and a high aspect ratio. Graphite has good electrical conductivity as well as good thermal conductivity. Graphite nanoplatelets can be obtained from expandable graphite, which is composed of natural graphite flake intercalated with acids, by appropriate thermal or microwave processing. During the processing, expandable graphite can be expanded up to hundreds of times over its pristine graphene sheets at the nano-scale level along the $\mathrm{c}$ axis of graphene layers [1-3]. Recently, graphite or graphene nanoplatelets have attracted considerable attention in academia and a large number of papers have dealt with this material [4-8].

Much attention has been directed to polyimides, which have excellent properties and heat resistance, for use as high performance polymers and composite materials. Phenylethynylterminated polyimide, which was named LaRC PETI-5 (simply referred to as PETI-5 hereafter) by the National Aeronautics and Space Administration (NASA) Langley Research Center in 1994 [9-11], has been used for composite matrices and adhesives in aircraft and aerospace applications for several reasons: its high glass transition temperature and toughness; its good mechanical, physical, chemical and thermal properties; and its adhesion capability and enhanced processibility [12].

For the last several years, many research efforts have been devoted to studying the effect of carbon nanoparticles like graphite nanoplatelets and carbon nanotubes on the electrical properties of various polymers [13-16]. However, studies on the effect of carbon nanoparticles on the electrical resistivity of PETI-5 have rarely been conducted. Consequently, the objective of this work is to understand how PETI-5 polyimide filled with exfoliated graphite nanoplatelets (EGN) at various loadings influences the fracture surfaces and the electrical resistivity depending on the EGN content. 
0.83<smiles>O=C1OC(=O)c2cc(-c3ccc4c(c3)C(=O)OC4=O)ccc21</smiles>

BPDA 0.85<smiles>Nc1ccc(Oc2cccc(N)c2)cc1</smiles>

APB<smiles>Nc1cccc(Oc2cccc(Oc3cccc(N)c3)c2)c1</smiles>

ODA

$+\quad 0.34$<smiles>O=C1OC(=O)c2cc(C#Cc3ccccc3)ccc21</smiles>

PEPA

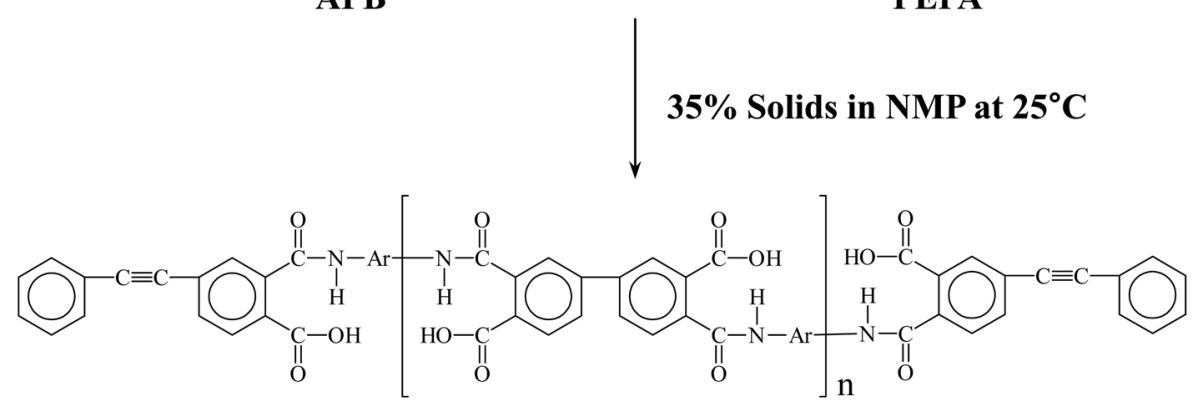

Phenylethynyl-terminated Amic Acid Oligomer

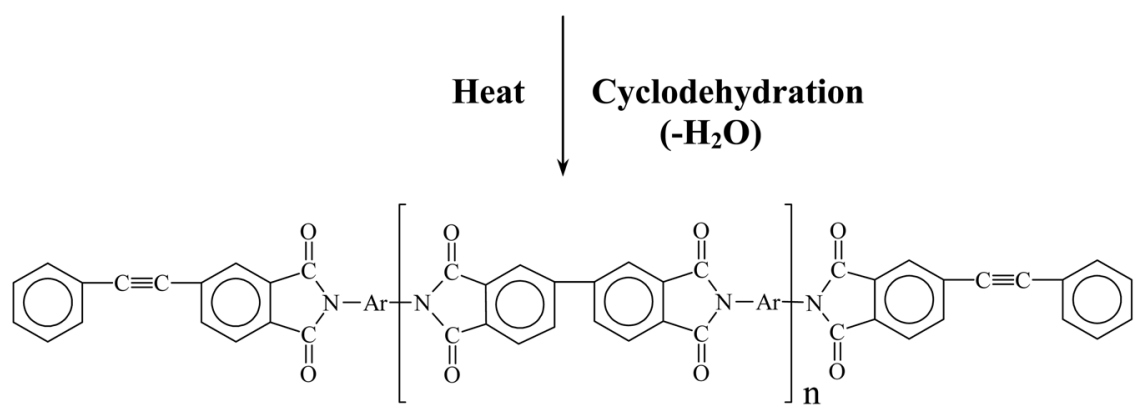

LaRC PETI-5 Polyimide<smiles>Cc1ccc(Oc2ccc(C)c(C)c2)cc1</smiles>

and<smiles>Cc1cccc(Oc2cccc(Oc3cccc(C)c3)c2)c1</smiles>

Fig. 1. Chemical scheme from the monomers to the PETI-5 polyimide through the amic acid oligomer. PETI-5: phenylethynyl-terminated polyimide.

\section{Experimental}

\subsection{Materials}

The PETI-5 imide oligomer used in this work was synthesized and supplied in liquid amic acid form from Imitec, Inc. (Schenectady, NY, USA). PETI-5 is a random copolymer with a number-average molecular weight of $2500 \mathrm{~g} / \mathrm{mol}$; it is prepared from 3,4'-oxydianiline (ODA), 1,3-bis(3-aminophenoxy) benzene (APB), and 3,3',4,4'-biphenyltetracarboxylic dianhydride (BPDA), end-capped with 4-phenylethynylphthalic anhydride (PEPA). The synthesis and chemistry of PETI-5 have been described in detail elsewhere. The solid content in N-methyl2-pyrrolidinone (NMP) as a solvent is about $35 \mathrm{wt} \%$. Fig. 1 provides the relevant chemical scheme, from the monomers to the PETI-5 oligomer and through amic acid. PETI-5 polyimide can be made from an oligomer by thermal curing, as has been described elsewhere [11,17].

\subsection{EGN and EGN/PETI-5 composites}

EGN were prepared through multiple pulverizing processes with expanded graphite (EG) particles. The EG was obtained by thermally treating at $900^{\circ} \mathrm{C}$ expandable graphite flakes (GrafGuard 160-50A), which were supplied by UCAR (USA), after intercalation with a mixture of sulfuric acid and nitric acid. The EG particles have a carbon content of about 97\%. The EG particles were finely pulverized using ultrasonic, ball-milling (alumina balls), and then, finally, vibratory ball-milling (zirconia 


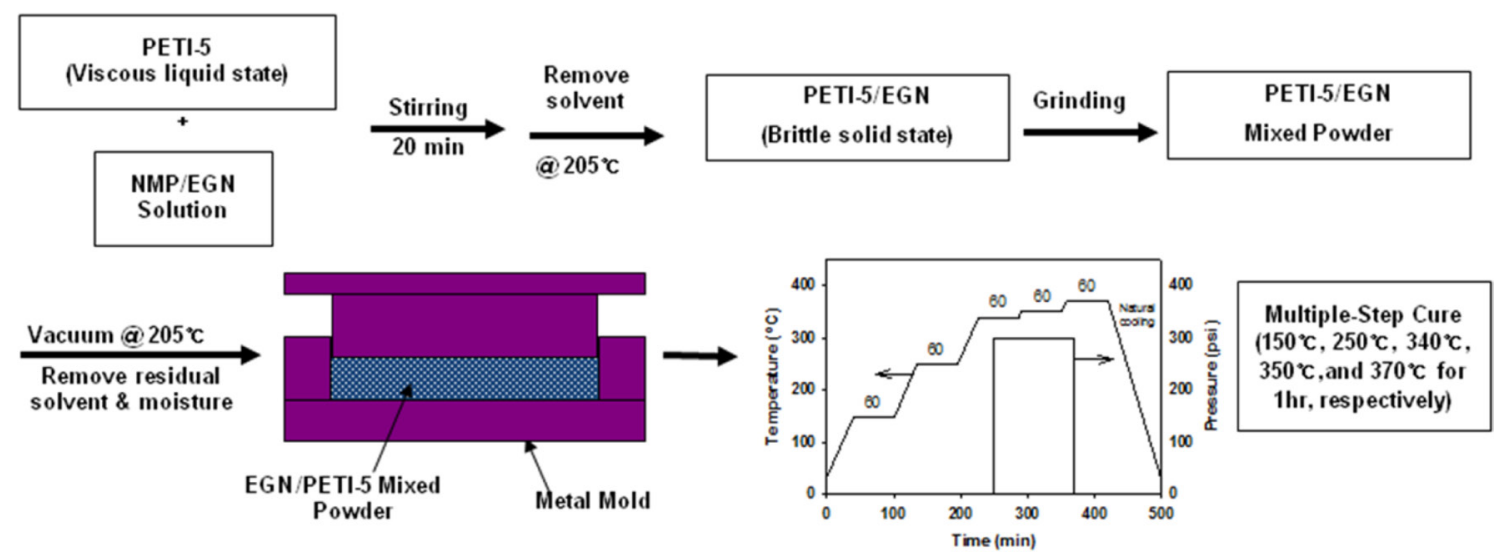

Fig. 2. Experimental procedure of EGN/PETI-5 composite processing including the time-temperature-pressure profile for curing. EGN: exfoliated graphite nanoplatelets, PETI-5: phenylethynyl-terminated polyimide.
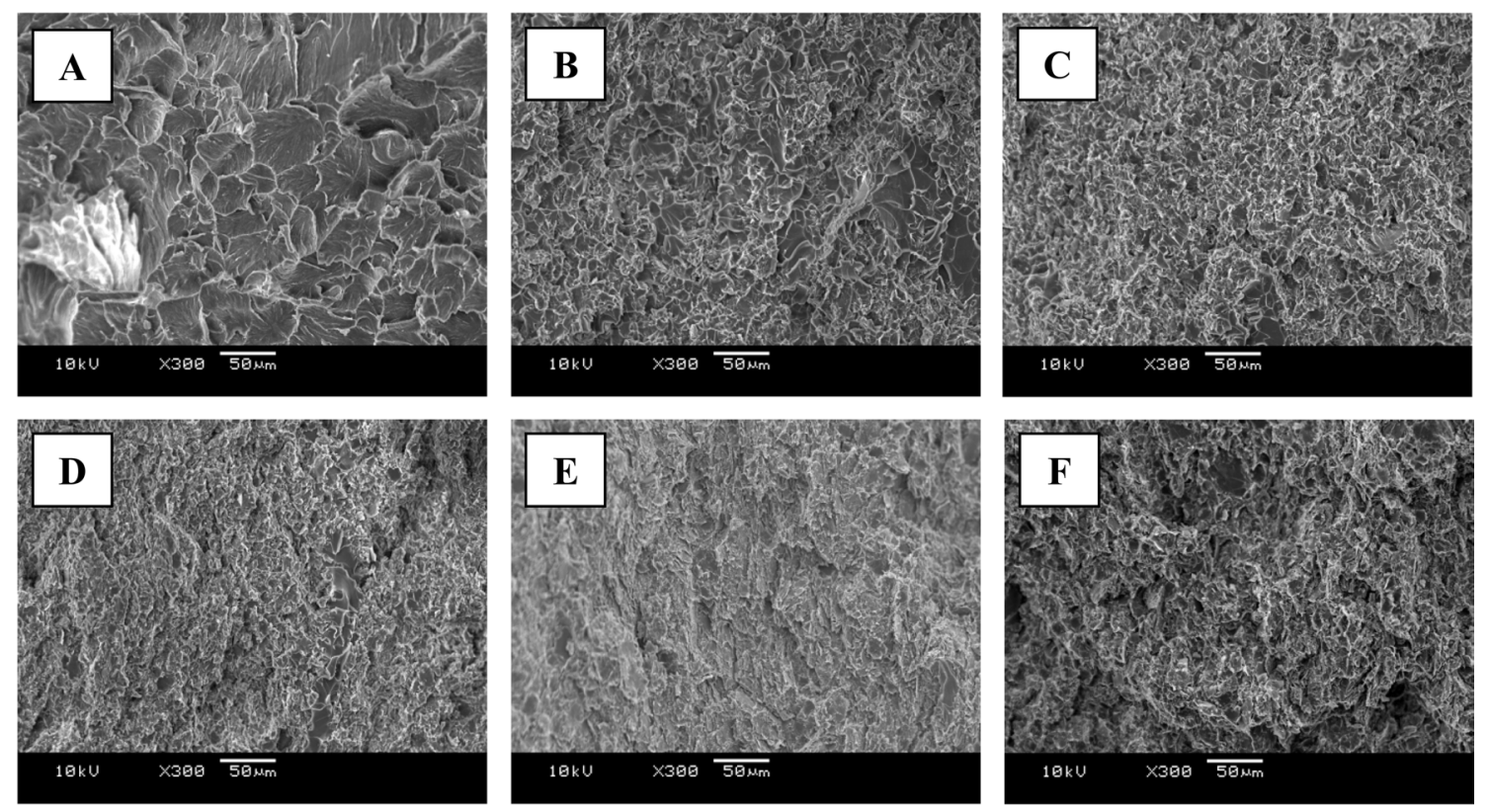

Fig. 3. Scanning electron microscope micrographs showing the fracture surfaces of (a) PETI-5 and EGN/PETI-5 composites: (b) EGN1/PETI-5, (c) EGN3/ PETI-5, (d) EGN5/PETI-5, (e) EGN10/PETI-5, and (f) EGN20/PETI-5 (300x). EGN: exfoliated graphite nanoplatelets, PETI-5: phenylethynyl-terminated polyimide.

balls) techniques, resulting in EGN. The average particle sizes measured were $19 \mu \mathrm{m}$ (ultrasonic), $7 \mu \mathrm{m}$ (ball-milling), and 1 $\mu \mathrm{m}$ (vibratory ball-milling); these size values were obtained by means of a particle size analyzer (Masterizer 2000, Malvern Instrument, Ltd.). It was found [1] that the average thickness of a single EGN with $1 \mu \mathrm{m}$ was about $5.4 \mathrm{~nm}$; the aspect ratio was about 185; the thin nanoplatelets maintained their average thickness and aspect ratio even after the pulverizing process, as similarly determined earlier [18].

To avoid aggregation during the composite fabrication, the EGN particles were first uniformly dispersed in NMP using an ultrasonic bath. The mixture of EGN/PETI-5 was stirred well with the PETI-5 oligomer and then the NMP was removed completely at $202^{\circ} \mathrm{C}$. In this step, the brittle yellowish solid of PETI5 was changed to a fine PETI-5 powder. Finally, five different
EGN/PETI-5 composites, according to the EGN loading, were fabricated in a stainless steel mold by compression molding using a hot-press (Carver 2518). The EGN loadings in the composite were $1,3,5,10$, and $20 \mathrm{wt} \%$. The PETI-5 specimen was also used for comparison. Fig. 2 displays the procedure of EGN/ PETI-5 composite processing, including the time-temperaturepressure profile for curing.

\subsection{Characterization}

The fracture surfaces of the PETI-5 and EGN/PETI-5 samples were observed using a scanning electron microscope (SEM, JSM-5900, JEOL). Prior to SEM observations, each sample was coated with gold by a sputtering method. The electrical resistivity was measured using impedance spectroscopy by applying the 

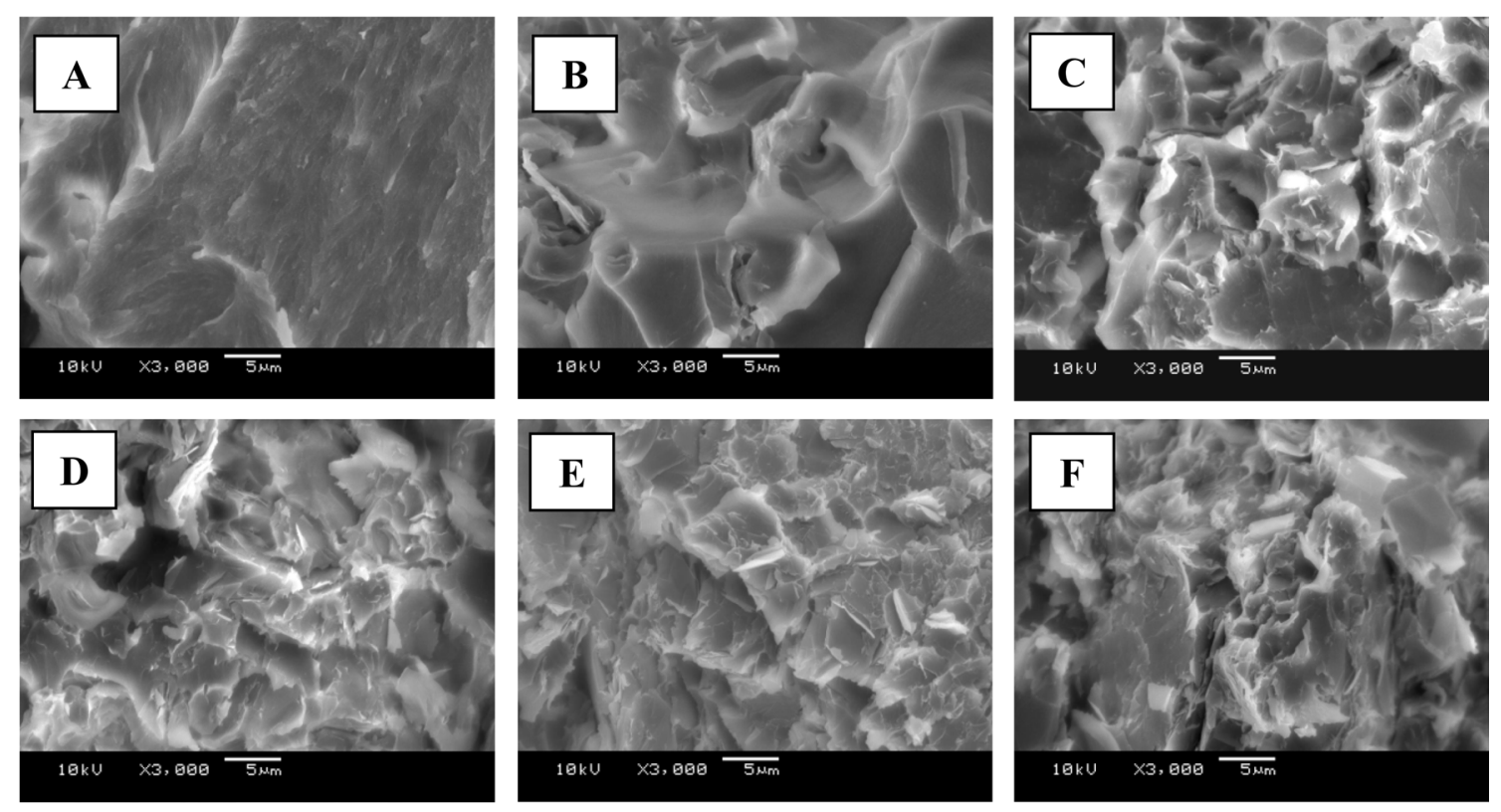

Fig. 4. Scanning electron microscope micrographs showing the fracture surfaces of (a) PETI-5 and EGN/PETI-5 composites: (b) EGN1/PETI-5, (c) EGN3/ PETI-5, (d) EGN5/PETI-5, (e) EGN10/PETI-5, and (f) EGN20/PETI-5 (3000×). EGN: exfoliated graphite nanoplatelets, PETI-5: phenylethynyl-terminated polyimide.

two-probe method at room temperature. Each data point was the average value of 3 to 5 measurements. The dimensions of each sample were $3.2 \mathrm{~mm} \times 5 \mathrm{~mm} \times 12.3 \mathrm{~mm}$.

\section{Results and Discussion}

Figs. 3 and 4 exhibit the fracture surfaces of the cured PETI-5 and EGN/PETI-5 composites with various EGN loadings, observed from the cross-section of each specimen at magnifications of $300 \times$ (Fig. 3) and $3000 \times$ (Fig. 4). The cured PETI-5 resin shows a typical ductile fracture pattern. Although PETI-5 is thermally curable, the fracture pattern is quite different from that of typical thermosetting polymers. It seems that the EGN/ PETI-5 composites, which were filled with small sized $(1 \mu \mathrm{m})$ EGN particles pulverized by vibratory ball-milling, exhibited good dispersion of EGN particles without particle aggregation into the PETI-5 matrix, as can be seen in Fig. 3. With a closer inspection of Fig. 4, it can be seen that with an increase of the EGN loading, the fracture surfaces became more ductile, leading to roughened surfaces. The graphite nanoplatelets were well distributed in the PETI-5 matrix, indicating the sharpened edges due to the platelet structure of EGN. It was expected that there would be close contacts between the PETI-5 and the EGN, reflecting the good interfacial adhesion between them.

It was found in our previous study [1] that the dynamic storage modulus of PETI-5 was increased and the coefficient of thermal expansion was decreased in the presence of graphite nanoplatelets. In addition, the glass transition temperature of PETI-5 was found to be influenced by the graphite nanoplatelets. These fracture surface patterns may be responsible for such property improvements. The well-dispersed EGN particles may play the role of reinforcement of the resulting composites, de-

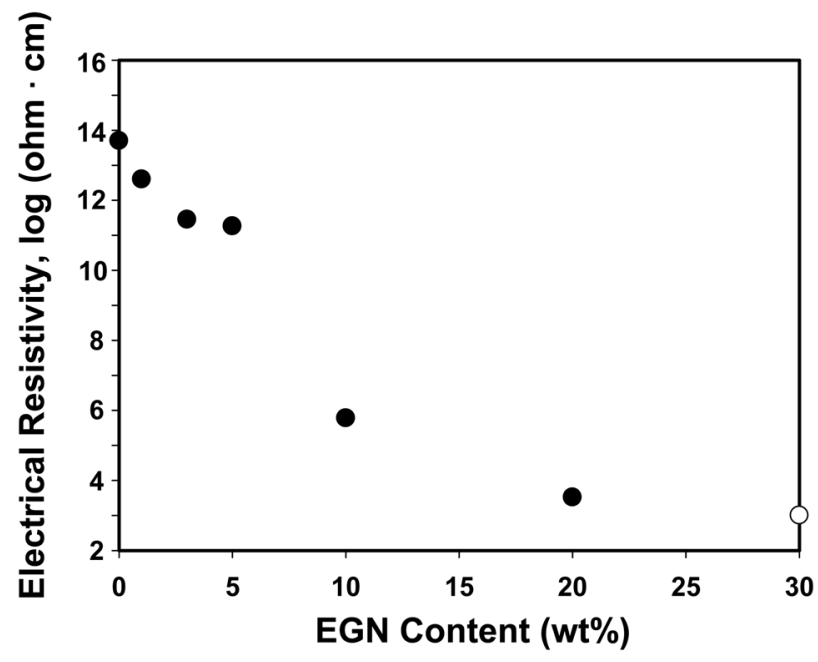

Fig. 5. Variations of the electrical resistivity of EGN/PETI-5 composites as a function of EGN loading. EGN: exfoliated graphite nanoplatelets, PETI5: phenylethynyl-terminated polyimide.

pending on the EGN content.

Fig. 5 displays the variations of the electrical resistivity of PETI-5 and EGN/PETI-5 composites as a function of EGN content. It can be clearly seen that the resistivity gradually decreased with the increase of the EGN loading. The reduction of the resistivity was profound between 5 and $10 \mathrm{wt} \%$. It seems that the percolation threshold occurred at $5 \mathrm{wt} \%$. In the case of compression molding, the lack of a preferred orientation of the fillers leads to the formation of a conductive network and thus lowers the percolation threshold [6]. This result was consistent with that in the earlier study on EGN-polypropylene composites 
processed by injection molding and compression molding, as reported by Kalaitzidou et al. [14]. Also, it was likely that the incorporation of small sized $(1 \mu \mathrm{m})$ graphite nanoplatelets into PETI-5 contributed to reducing the EGN content for the percolation threshold because increasing the number of EGN-PETI-5 interfaces via the presence of small EGN particles resulted in increasing the contact points between the EGN and PETI-5. At $20 \mathrm{wt} \%$, the electrical resistivity decreased to about $3 \times 10^{3}$ $\mathrm{ohm} \cdot \mathrm{cm}$. It was expected that the resistivity would be about $10^{3}$ $\mathrm{ohm} \cdot \mathrm{cm}$ at $30 \mathrm{wt} \%$ of EGN.

\section{Conclusions}

Depending on the EGN content, the incorporation of EGN into PETI-5 influenced the electrical resistivity and the fracture surface morphology. Small sized $(1 \mu \mathrm{m})$ graphite nanoplatelets were well distributed in the PETI-5 matrix, indicating the good interfacial adhesion between the EGN particles and the PETI-5. With increased EGN loading, the fracture surfaces became more ductile, leading to roughened surfaces. The electrical resistivity of PETI-5 was gradually decreased with increased EGN loading. The reduction of the resistivity was profound between 5 and 10 $\mathrm{wt} \%$ of EGN, exhibiting a percolation threshold at $5 \mathrm{wt} \%$.

\section{References}

[1] Cho D, Lee S, Yang G, Fukushima H, Drzal LT. Dynamic mechanical and thermal properties of phenylethynyl-terminated polyimide composites reinforced with expanded graphite nanoplatelets. Macromol Mater Eng, 290, 179 (2005). http://dx.doi.org/10.1002/ mame. 200400281.

[2] Lee S, Cho D, Drzal LT. Real-time observation of the expansion behavior of intercalated graphite flake. J Mater Sci, 40, 231 (2005). http://dx.doi.org/10.1007/s10853-005-5715-0.

[3] Chen GH, Wu DJ, Weng WG, Yan WL. Preparation of polymer/ graphite conducting nanocomposite by intercalation polymerization. J Appl Polym Sci, 82, 2506 (2001). http://dx.doi.org/10.1002/ app.2101.

[4] Li J, Wong PS, Kim JK. Hybrid nanocomposites containing carbon nanotubes and graphite nanoplatelets. Mater Sci Eng A, 483-484, 660 (2008). http://dx.doi.org/10.1016/j.msea.2006.08.145.

[5] Kim S, Do I, Drzal LT. Multifunctional xGnP/LLDPE nanocomposites prepared by solution compounding using various screw rotating systems. Macromol Mater Eng, 294, 196 (2009). http:// dx.doi.org/10.1002/mame.200800319.

[6] Kalaitzidou K, Fukushima H, Drzal L. A route for polymer nanocomposites with engineered electrical conductivity and percolation threshold. Materials, 3, 1089 (2010). http://dx.doi.org/10.3390/ ma3021089.

[7] Liu W, Do I, Fukushima H, Drzal LT. Influence of processing on morphology, electrical conductivity and flexural properties of exfoliated graphite nanoplatelets-polyamide nanocomposites. Carbon Lett, 11, 279 (2010).

[8] Karevan M, Pucha RV, Bhuiyan MA, Kalaitzidou K. Effect of interphase modulus and nanofiller agglomeration on the tensile modulus of graphite nanoplatelets and carbon nanotube reinforced polypropylene nanocomposites. Carbon Lett, 11, 325 (2010).

[9] Hergenrother PM, Smith JG Jr. Chemistry and properties of imide oligomers end-capped with phenylethynylphthalic anhydrides. Polymer, 35, 4857 (1994). http://dx.doi.org/10.1016/00323861(94)90744-7.

[10] Jensen BJ, Bryant RG, Smith JG Jr, Hergenrother PM. Adhesive properties of cured phenylethynyl-terminated imide oligomers. JAdhes, 54, 57 (1995). http://dx.doi.org/10.1080/00218469508014381.

[11] Cho D, Drzal LT. Characterization, properties, and processing of LaRC PETI-5 as a high-temperature sizing material. II. Thermal characterization. J Appl Polym Sci, 75, 1278 (2000). http:// dx.doi.org/10.1002/(sici)1097-4628(20000307)75:10<1278::aidapp9>3.0.co;2-m.

[12] Cho D, Choi Y, Drzal LT. Characterization, properties, and processing of larc peti- $5 \circledR$ as a high-temperature sizing material: III. Adhesion enhancement of carbon/BMI composites. J Adhes, 79, 1 (2003). http://dx.doi.org/10.1080/00218460309559.

[13] Kim S, Seo J, Drzal LT. Improvement of electric conductivity of LLDPE based nanocomposite by paraffin coating on exfoliated graphite nanoplatelets. Composites A, 41, 581 (2010). http:// dx.doi.org/10.1016/j.compositesa.2009.05.002.

[14] Kalaitzidou K, Fukushima H, Askeland P, Drzal L. The nucleating effect of exfoliated graphite nanoplatelets and their influence on the crystal structure and electrical conductivity of polypropylene nanocomposites. J Mater Sci, 43, 2895 (2008). http://dx.doi. org/10.1007/s10853-007-1876-3.

[15] Li J, Vaisman L, Marom G, Kim J-K. Br treated graphite nanoplatelets for improved electrical conductivity of polymer composites. Carbon, 45, 744 (2007). http://dx.doi.org/10.1016/j.carbon.2006.11.031.

[16] Ma PC, Liu MY, Zhang H, Wang SQ, Wang R, Wang K, Wong YK, Tang BZ, Hong SH, Paik KW, Kim JK. Enhanced electrical conductivity of nanocomposites containing hybrid fillers of carbon nanotubes and carbon black. ACS Appl Mater Interfaces, 1, 1090 (2009). http://dx.doi.org/10.1021/am9000503.

[17] Cho D, Choi Y, Drzal LT. Simultaneous monitoring of the imidization and cure reactions of LaRC PETI-5 sized on a braided glass fabric substrate by dynamic mechanical analysis. Polymer, 41, 4611 (2001).

[18] Fukushima H. Graphite Nanoreinforcements in Polymer Nanocomposites [PhD Thesis], Michigan State University, East Lansing, MI (2003). 